\title{
Chapter 19 \\ Reskill to Rebuild: Coursera's Global \\ Partnership with Government to Support \\ Workforce Recovery at Scale
}

\author{
Alison Lands and Chad Pasha
}

\section{Abbreviations}

$\begin{array}{ll}\text { APAC } & \text { Asia and the Pacific } \\ \text { COL } & \text { Commonwealth of Learning } \\ \text { COVID-19 } & \text { coronavirus disease } \\ \text { E2i } & \text { Employment and Employability Initiative } \\ \text { ILO } & \text { International Labour Organization } \\ \text { MEA } & \text { Middle East and Africa } \\ \text { MOOC } & \text { massive open online course }\end{array}$

\subsection{Introduction}

Within the context of a modern learning society, few technological disruptions embody the democratizing ethos of accessible, lifelong learning as the innovation of massive open online courses (MOOCs), which leverage technology to make academic instruction broadly available to the public. Coursera, an educational technology startup founded in 2012 by Professors Daphne Koller and Andrew Ng of Stanford University, was an early progenitor of the MOOC ecosystem, and the company

\author{
A. Lands (凶) \\ Skills Transformation, North America, Coursera, Mountain View, CA, USA \\ e-mail: alands@coursera.org \\ C. Pasha \\ Global Government Partnerships, Coursera, Mountain View, CA, USA \\ e-mail: cpasha@coursera.org
}


(now with over 70 million global learners ${ }^{1}$ ) has weathered the peaks and troughs of MOOCs" popularity, emerging as an "edtech" industry leader that provides affordable access to the world's leading university and industry content, with a focus on in-demand digital skills that are forecasted to drive growth in the fourth industrial revolution.

Although industry pundits once questioned the long-term viability of MOOCs (and online instruction generally) to transform the education ecosystem, the coronavirus disease 2019 (COVID-19) pandemic, as in so many other contexts, created a "forcing" mechanism putting online learning to the test. In this virtual environment, Coursera and other MOOCs have fared well in comparison to other learning modalities. The company's response to the pandemic showcases the potential for online learning applications in postsecondary education as well as workforce reskilling. In this context, Coursera, through its mission to improve lives through learning, has been given an unprecedented opportunity to test "the art of the possible" for the future of platform technology in education and lifelong learning.

\subsection{How Coursera and Platform Technologies Power the Modern Learning Society}

As an enterprise, Coursera partners with top global universities (such as Yale, INSEAD, and Imperial College) and industry partners (such as Google, IBM, and the Boston Consulting Group) to source high-quality instructional content, which is hosted on Coursera's online platform. These courses are made available to corporations, academic and civic institutions, and individuals to consume on-demand (Fig. 19.1). At present, learners access over 4400 online courses and 600 guided projects spanning 11 subject matter domains with an emphasis on business, computer science, and data skills, which are in high global demand across sectors.

Coursera's content is accessible on demand, as well as via mobile app or download (for offline access). Content is presented in an asynchronous format to accommodate adult work and study schedules. Credentials are "stackable" in nature-from a short-form applied project requiring an investment of 1-2 hours, to the full postgraduate online degree, with an emphasis on professional certificates and specializations that support mastery of career-oriented skills. Learners can audit courses for free, but may elect to purchase a subscription or course credential that allows them to certify and share their achievements online. Through its open access, job-ready skills focus, flexible delivery model, and global reach for learners of all proficiency levels, Coursera models the values of a learning society to extend education beyond the classroom, supporting both lifelong learning and workforce development.

\footnotetext{
${ }^{1}$ Unless otherwise specified, all statistical data referencing Coursera is Coursera data as of September 2020.
} 


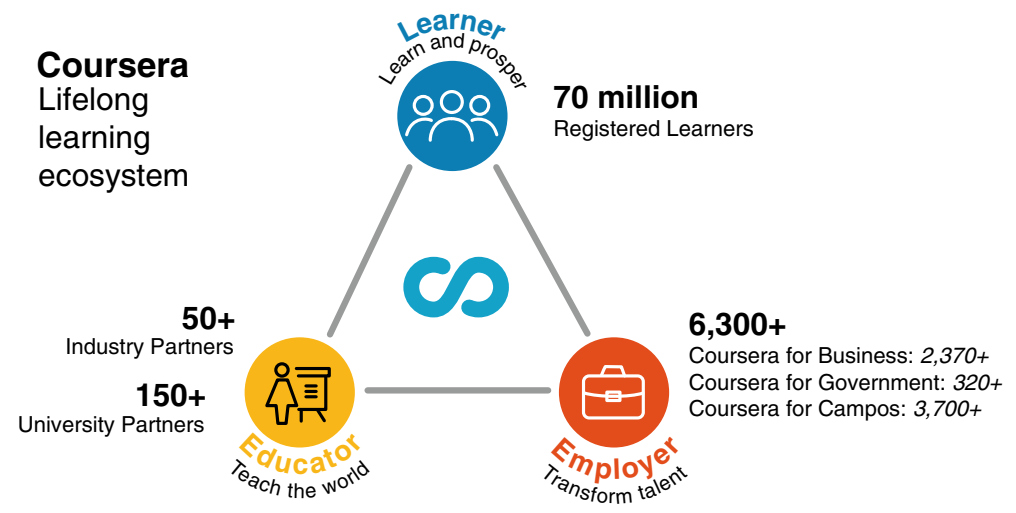

Fig. 19.1 Coursera's cross-sector ecosystem for skills transformation (Coursera's online learning platform serves over 70 million global learners, as well as an ecosystem of institutional and industry partners). Source Coursera

Coursera also serves the larger policy aspirations of a learning society by crafting a common skills nomenclature across educational, commercial, and government sectors. Coursera learners take 80+ million assessments annually in 40,000 skills; across 100+ countries; 50+ industries; and 7500 companies, and the learning patterns of this global community constitute a rich dataset to observe how the world is learning, which skills matter, and where demand for those skills is concentrated. The platform's courses and assessments feed a dynamic skills taxonomy known as the Skills Graph, which is powered by a series of machine learning models that continuously ingest search and performance data from instructors, universities, individual learners, companies, governments and open source taxonomies to add new skills and calibrate to external standards over time. By analyzing diverse sources of internal and external information, Coursera's Skills Graph is able to capture major changes in the skills landscape, providing a current view of skills demand, as well as a "common language" that universities, governments, and businesses can use to translate their respective skills needs.

Coursera's platform also provides a cohesive environment for the learner to integrate skills acquired throughout the workforce lifecycle. Students often use Coursera to supplement coursework, to access offerings otherwise unavailable to them, and to prepare for the transition from academia to employment. Adult learners primarily use Coursera on the job as part of a corporate learning and development program, in parallel to their work or job search to prevent skills erosion, and to stay relevant in the job market. Government clients use the platform both to upskill civil servants; and to deliver workforce development programs to improve the quality of the labor shed, reskill unemployed workers, and help them reattach to the labor market. Throughout a working lifetime, Coursera represents a nexus for reskilling, a home base from which to acquire the skills needed to succeed today, but also a guide to maintain skills relevancy as business models evolve and new technologies emerge. 
In this way, the company and its technology form a foundational infrastructure for skills transformation as well as connective tissue to serve learners from campus, to career, and beyond.

\subsection{Current State of Skills Across Asia and the Pacific}

Coursera presently has over 16 million learners across Asia and the Pacific, with significant adoption in the People's Republic of China; India; Pakistan; Singapore; and Taipei,China.

In addition to a cadre of regional university partnerships, Coursera's engagement in the region also includes a diverse array of state and quasi-governmental organizations focused on reskilling both civil servants and citizens at scale, as in the following examples:

(i) Asian Development Bank, which is supporting a program to build the capacity of Kazakhstan civil servants across central ministries undergoing digital transformation;

(ii) Malaysia Digital Economy Corporation, where 12,000+ unemployed citizens are receiving training for in-demand job skills including software engineering, data science, and cloud computing;

(iii) Department of Science and Technology, Philippines, where 16,000+ citizens are focused on developing cybersecurity, communications, and marketing skills; and

(iv) Pakistan, where Coursera is working with the Higher Education Commission and the Punjab Skills Development Fund to upgrade the national education system.

Online learning is a critical component of corporate learning and development strategies to efficiently upskill employees in their roles, and to do so at a lower cost compared to traditional instructor-led training. Coursera also works with leading businesses globally to train their employees in data science, finance, technology, and leadership skills to perform competitively within their industries. In Asia and the Pacific, these corporate clients include Samsung, Tata, Temasek, Toyota, and many others. Recognizing the importance of technology and data skills, computer science currently represents the most popular subject for the Coursera learners within the region, along with a substantive mix of business and data science competencies, specifically the Python programming language, data analysis, and business analytics.

Given the company's wealth of global data, Coursera publishes an annual Global Skills Index (Coursera 2020), which benchmarks 60 nations with respect to their learners' proficiencies in the domains of business, technology, and data. In comparison to other regions, Asia and the Pacific is, in aggregate, an emerging region for skills development, with mid-level rankings in business, and lower levels of achievement in technology and data science (Fig. 19.2). 


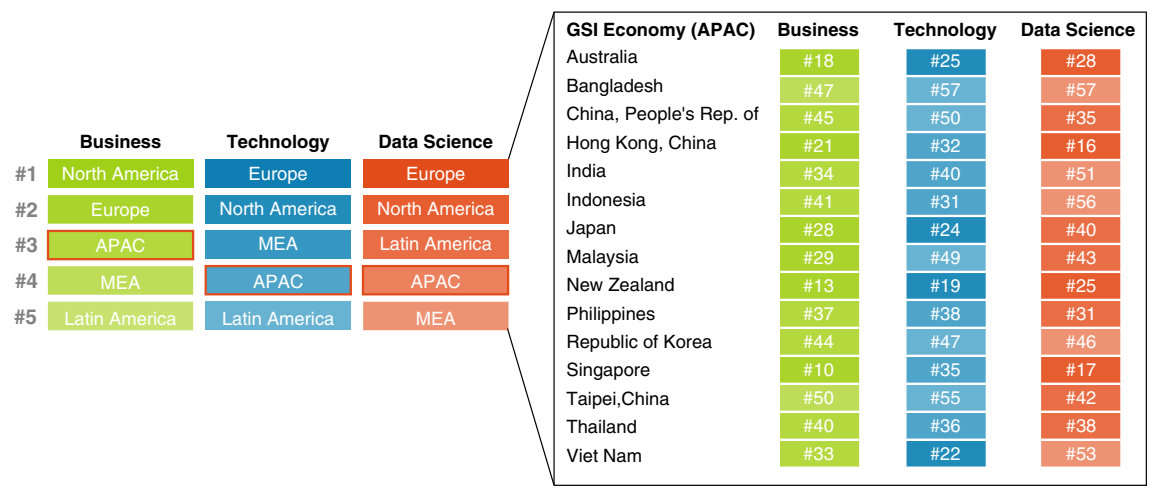

Fig. 19.2 Skills rankings from the 2020 Global Skills Index (Coursera publishes an annual Global Skills Index, which benchmarks 60 nations with respect to their learners' proficiencies in the domains of business, technology, and data). APAC = Asia and the Pacific, GSI = Global Skills Index, MEA = Middle East and Africa. Source Coursera. 2020. Global Skills Index. https://www.coursera.org/gsi

Despite the increasing focus on human capital investment by Coursera's clientele, skills development across the region remains unequal, highlighting a stark contrast between industrialized and emerging economies' skills proficiency. While Australia, New Zealand, and Singapore have more resources per capita to invest in education and upskilling, developing economies-including Bangladesh, Pakistan, and the Philippines - are among the lowest skilled of Coursera's global users. These countries spend less on education as a percentage of gross domestic product (GDP) and have higher proportions of low-skilled workers (HR in Asia 2016).

Asia and the Pacific, like most regions outside of Europe, faced a skills deficit prior to the COVID-19 pandemic, one that could only be exacerbated by skills erosion resulting from a protracted economic shutdown that has also impacted the region's education systems. Given the substantive positive correlations between skills proficiency and labor force participation, returns to capital, GDP per capita, and social equity (Coursera 2020), Asia, like much of the world, is receiving through COVID-19 an invitation and a challenge to embrace new forms of workforce development and upskilling.

\subsection{The "Great Lockdown" of 2020 and Coursera's Workforce Recovery Initiative}

If MOOCs were discounted as a fading technology as recently as 2017 (Warner 2017), then few proof points could more fully demonstrate the utility of online learning platforms so clearly as the "Great Lockdown" of 2020. Within weeks of the worldwide alert over COVID-19, campuses in over 188 countries across the globe suspended operations, many of them dismissing students mid-semester, and hastily 
shifting to online delivery, affecting as many as 1.8 billion students, or $91 \%$ of the global student body (Strauss 2020). Of the 200 million higher education students whose studies were disrupted by COVID-19, $80 \%$ were located in countries with emerging or lagging skills. School closures disrupted higher education for millions of students in countries already in need of more accessible learning.

In parallel, hundreds of millions of workers lost their jobs as a result of full or partial lockdown measures affecting almost 2.7 billion-four in five of the world's workers, according to the International Labour Organization (ILO), with particularly sharp effects in the global manufacturing and service sectors (UN News 2020). Applications for unemployment benefits soared, in parallel with the announcement of bankruptcies across industries and firms of all sizes. Even as the economic shutdown resulted in mass worker displacement and deepening economic inequality on a global scale, the resulting lockdown of most daily activities to prevent virus transmission, and the unexpected acceleration of digital consumption of goods and services to provide workarounds to the challenges of a postpandemic world, further hastened the specter of skills erosion. With students out of school and adults out of work, an inability to maintain and improve upon digital skills could make workers vulnerable to permanent underemployment or displacement from the labor market (Lund et al. 2020).

During this same time period, Coursera experienced an unprecedented influx of user enrollments-over 15 million people in the first 4 weeks of the shutdown, for a $644 \%$ increase over the prior year. The dramatic increase in volume was mirrored across both geographies and subject domains, as displaced learners and workers used learning as a tool to cope with the uncertainty of their environment.

In response to these exigent and unprecedented circumstances, Coursera extended no-cost access to its course catalog to campuses and displaced workers. The Coursera for Campus Coronavirus Response Initiative made Coursera's platform available to help faculties virtualize instruction, as well as leverage Coursera content to extend course availability during the shutdown. Coursera also developed a machine learning algorithm to assist campuses in mapping their existing syllabi and course catalogs to Coursera's to rapidly identify areas of alignment. The availability of Coursera to campuses through this initiative resulted in over 29,000 global inquiries from faculty, who from March to September 2020 launched over 6000 virtual programs to deliver remote learning to students at scale.

In parallel, the Coursera launched a Workforce Recovery initiative to extend unlimited, no-cost licenses to displaced workers, accessible through their governments, including ministries of labor, education, and economic development; as well as to regional and local intermediaries. To reduce decision fatigue by unemployed workers, align training to areas of robust hiring demand, and streamline implementation by government agencies, the initiative was rolled out with curated collections of courses aligned to common workforce development use cases, including job readiness training, entrepreneurship, upskilling for digital career paths, and basic digital literacy aimed at a broad population.

The intent of the Workforce Recovery effort by Coursera was two-fold: to support short-term recovery, as well as provide a longer-term resource to governments around 
the world to invest in online workforce development and digital upskilling at scale. During the shutdown, the initiative sought to provide online learning as a balm to comfort displaced workers and those experiencing a lockdown (Zhang et al. 2018), encouraging them to use their time productively and possibly secure a better job than the one they lost.

Beyond the pandemic, Coursera sought to apply online reskilling as a tool for large-scale economic development and workforce transformation: to serve as a partner of governments and help them deliver digital skills training for unemployed and underemployed workers; align Coursera content to industry requirements; and administer learning at scale through their regional workforce development ecosystems. All of these were to create an agile, scalable resource that supports lifelong learning - the very foundation of a learning society.

\subsection{Initial Results of Coursera's Partnerships with Government and Education Institutions}

As of September 2020, Coursera's impact partnerships had reached a total of 2 million students enrolled in more than 3700 campuses through the Campus Response initiative; including 1 million displaced workers in over 110 countries through the Workforce Recovery initiative. While these affected populations all battled the same global malady, the approaches taken to leverage Coursera's tools took on the unique flavor and characteristics of the local environment, and political and cultural norms.

If one feature could characterize the adoption of Coursera by participating governments in response to the economic shutdown, it would be the customized approach that agencies took in adapting the platform to their regional economies and learner populations; and personalizing the delivery model, courses offered, channels of communication, and messaging to maximize efficacy within their existing ecosystem. That said, a number of applications prevailed globally:

(i) Basic remedial upskilling. Tailored for the unemployed, upskilling focused on subjects including business English and professional communication, as well as job readiness training in subjects like time management, personal accountability, critical thinking and teamwork, and computer literacy in popular office productivity applications such as spreadsheets.

(ii) Digital literacy at a population level. Anchored by professional certificates and specialization programs aligned to job training for digital occupations, such as the Google IT Support Professional Certification, this application prepared nontechnical workers for an entry-level role in technology.

(iii) Customized career learning paths. Learning paths were also customized for a population of learners, informed by industry and shaped around regional economic development priorities. In some cases, digital badges recognized by employers were assembled by the workforce partner for their learners to pursue. 
(iv) Youth employment training programs. These programs targeted both young adults who had missed opportunities to work in their community for pay, as well as out-of-school, out-of-work youth, to help them gain access to meaningful employment.

Even though this mass unemployment event was historically unique, displacing both highly skilled workers alongside those more intractably unemployed, few governments made access to Coursera licenses available to workers without some form of hands-on intervention. While it remains to be seen whether pandemic-displaced workers could efficiently self-serve in an online learning program, in most cases, the government elected to place its imprimatur on the workforce recovery program and to directly engage residents to participate.

Throughout Asia and the Pacific, some case examples highlight the diverse approaches to workforce recovery within the region (see Box 19.1).

\section{Box 19.1 Initiatives on Workforce Recovery in Select Countries in Asia and the Pacific}

- The Malaysia Digital Economy Corporation sought enrollment across the country that aligned to the nation's industrial strategy. As of October 2020, over 10,000 learners have enrolled in a program to reskill in accordance with economic development priorities.

- The Philippines' Department of Science and Technology program experienced the second-largest Coursera utilization in Asia and the Pacific, with more than 5000 enrolled learners. This partnership built on previous partnerships with the Philippine government from 2017, which trained workers in data science, artificial intelligence, cybersecurity, and robotics.

- Within India, the Odisha Skills Development Authority, Tamil Nadu Skill Development Corporation, Uttar Pradesh Skill Development Mission, and Telangana Academy for Skills and Knowledge launched statewide workforce recovery programs, building on earlier workforce development efforts with Andhra Pradesh Skills Development Corporation, where over 8000 learners were trained on a range of information technology skills.

- In Singapore, the Employment and Employability Institute equipped 4000 citizens with cutting-edge skills needed for the national economy. The Singapore Civil Service College enabled government officials to upskill in data science, leadership, and technology skills.

- In Uzbekistan, Coursera worked with multiple ministries and centers, including the Innovation Technology and Strategy Center under the Ministry of Public Education, the IT Park, and the Ministry of Higher Education, to train tens of thousands of citizens on a range of business, technology, and data skills.

- The Ministry of Labour and Human Resources in Bhutan is training hundreds of Bhutanese citizens in industry-relevant skills. 
- In Sri Lanka, the government is training thousands of unemployed and youth on technical and human skills, through the National Library of Sri Lanka under the Ministry of Education.

- Bangladesh national government agencies, where Coursera is collaborating with the Commonwealth of Learning (COL), are training youth, women, and vulnerable groups on key skills needed to transform their lives.

- In addition to these state-level efforts, under the partnership with COL and regional library associations, a diverse range of learners are receiving online technical and soft skills training across Australia, Cambodia, Fiji, Guam, Indonesia, Kiribati, Maldives, Nauru, New Zealand, Papua New Guinea, Samoa, Solomon Islands, Thailand, Tonga, Tuvalu, Vanuatu, and Viet Nam.

- Coursera and COL are planning to hold a joint virtual convocation in 2021 with senior ministers from across Asia and the Pacific to showcase graduates of the Coursera Workforce Recovery program and testimonials of employers who have hired them.

Source Coursera

\subsection{Lessons Learned from Coursera's Pandemic Response Efforts}

As of September 2020, the Workforce Recovery and Campus Response initiatives are both ongoing; as such, the space for reflection on their impact and efficacy is limited. In a historic year of global tumult and an unprecedented response to the pandemic crisis, stakeholders across the ecosystem have gained invaluable insights on what it takes to provide reskilling at scale.

An examination of lessons learned has yielded best practices that can and should be continued. These include the following:

(i) Rapid intervention for affected campuses. This finding was evidenced by 156 universities from the Southeast Asian region, which launched Coursera programs with high utilization rates. These insulated students from the negative impact of COVID-19 on their academic progress and outcomes.

(ii) Collective action through the work of a consortium. Collective action, such as that demonstrated by the Commonwealth of Learning, provided connective tissue across partners, as well as technical assistance and support to the response effort.

(iii) Adopting an industry focus and partnering with economic development entities. Industry alignment to inform curriculum design strengthens the virtuous circle between learning and a connection to near-term employment.

(iv) Maintaining a long-term perspective. This "future focus" emphasizes digital skills and thoughtful design around an aspirational future labor market, 
recognizing the significant lag time to recovery, in addition to committing to train residents beyond the immediacy of "lifeboat jobs" needed for financial survival, to those that promote long-term economic mobility.

Conversely, lessons learned that can serve to iteratively improve the experience of governments attempting to deliver workforce recovery and upskilling solutions via online remote learning in the future include the following:

(i) Recognize technology capabilities. Within a country, technological abilities can be a limiting factor to service delivery and program efficacy (including population digital literacy, access to broadband and hardware).

(ii) Address operational concerns around privacy. Inadequate privacy systems limit the accessibility of citizen data and records to conduct outreach and provide ongoing support.

(iii) Overcome local language barriers. This finding includes limited availability of translated materials, for which machine translation may provide a future solution.

(iv) Identify institutional or political resistance to a perceived "risk" of failure. In a high-stakes environment, bureaucratic processes can slow speed to action.

(v) Face the fundamental issue of scale. Many local agencies are not equipped to adapt their operations to the scale of the pandemic, lacking either staffing, resources, or internal human capital to structure and deploy a program, even one that did not draw on existing budgets.

What then does it take to reskill a workforce at scale? Drawing on the interactions with Coursera's partners in workforce recovery, the following are some of the critical success factors:

(i) Maintain a long-term perspective. Avoid expectations of a "quick fix" or immediate results. Cultivate a healthy cross-sector ecosystem of relationships among political leadership and those responsible for ground-level implementation of workforce development and education.

(ii) Maintain mutual humility. Respect is necessary between the public sector, educators, and employers who benefit from their labor, as well as recognition that the process will be iterative. There should be a willingness for industry to inform (but not dictate) the learning program, and also a demonstrated commitment on behalf of the corporate sector to employ and continue to train the workers who will undergo a reskilling program.

(iii) Exercise creativity. The most essential ingredient in addressing a "wicked problem" such as workforce development is creativity - the flexibility to explore and push the boundaries of what have existed prior; and to create a fluid system that draws on the best of educational pedagogy and tradition, while designing a method to continuously reskill workers for the jobs we may not yet be able to conceive. 


\subsection{Looking Ahead}

A recent New York Times analysis (Leatherby and Gelles 2020) highlighted rapidly accelerating rates of postpandemic consumption for digital goods and services, placing the demand for digitally savvy workers on fast-forward, and expanding the landscape in which corporations search for talent to encompass the farthest reach of the internet itself. While we might have suspected most companies to be ill-equipped to pivot to a weightless economy overnight, many in fact did just that, and the resulting aftershocks that are being felt throughout the macroeconomy underscore how many global workers risk falling further behind unless longer-term interventions to close the digital divide and digital skills gap succeed across sectors.

Online learning platforms (like Coursera) are an example of responsive, agile, scalable workforce development that can adapt at the speed of business, and improve on delivery to overcome many of the previous challenges of instructor-led or classroom training for working adults and the out-of-work. As evidenced by the company's response to the COVID-19 pandemic, these learning technologies not only support operational continuity across sectors, but also help learners themselves sustain focus on their personal goals and cultivate well-being during a stressful episode. This helps them minimize lapses in momentum and stave off skills erosion, which is now becoming essential to achieve a robust economic recovery.

As of September 2020, learners enrolled in Coursera's Workforce Recovery had completed over 10 million hours of training to reskill and regain traction in the labor market. The accelerating demand for digital skills and potential for rolling future waves of economic disruption will increase the need for both remote workers and reskilling resources. Indeed, the stage is now set for a generation of students and workers to embrace self-paced, self-directed online learning as never before. Now, more than ever, it is incumbent upon governments, universities, employers, and platforms to collaborate on an unprecedented scale to encourage this adaptation to the future of work, empowering learners in all corners of the world to successfully navigate the skills landscape successfully and to stake their claim within it.

\section{References}

Coursera. 2020. Global Skills Index. https://www.coursera.org/gsi.

HR in Asia. 2016. Asia's emerging economies face severe skilled labour shortage: WAI report finds. https://www.hrinasia.com/news/asias-emerging-economies-face-severe-skilled-lab our-shortage-wai-report-finds.

Leatherby, L., and D. Gelles. 2020. How the virus transformed the way Americans spend their money. https://www.nytimes.com/interactive/2020/04/11/business/economy/coronavirus-us-eco nomy-spending.html.

Lund, S., et al. 2020. Lives and livelihoods: Assessing the near-term impact of COVID-19 on US workers. McKinsey \& Company. https://www.mckinsey.com/industries/public-and-social-sector/ our-insights/lives-and-livelihoods-assessing-the-near-term-impact-of-covid-19-on-us-workers. 
Strauss, V. 2020. Schools of more than 90 percent of the world's students closed during this pandemic. This graphic shows how fast it happened. https://www.washingtonpost.com/educat ion/2020/04/06/schools-more-than-90-percent-worlds-students-closed-during-this-pandemicthis-graphic-shows-how-fast-it-happened/.

UN News. 2020. COVID-19: Impact could cause equivalent of 195 million job losses, says ILO chief. https://news.un.org/en/story/2020/04/1061322.

Warner, J. 2017. MOOCs are dead ... what's next? Uh-oh. https://www.insidehighered.com/blogs/ just-visiting/moocs-are-dead-whats-next-uh-oh.

Zhang, C., C.G. Myers, and D.M. Mayer. 2018. To cope with stress, try learning something new. Harvard Business Review. https://hbr.org/2018/09/to-cope-with-stress-try-learning-someth ing-new.

The opinions expressed in this chapter are those of the author(s) and do not necessarily reflect the views of the Asian Development Bank, its Board of Directors, or the countries they represent.

Open Access This chapter is licensed under the terms of the Creative Commons Attribution-NonCommercial 3.0 IGO license (http://creativecommons.org/licenses/by-nc/3.0/igo/) which permits any noncommercial use, sharing, adaptation, distribution and reproduction in any medium or format, as long as you give appropriate credit to the Asian Development Bank, provide a link to the Creative Commons license and indicate if changes were made.

Any dispute related to the use of the works of the Asian Development Bank that cannot be settled amicably shall be submitted to arbitration pursuant to the UNCITRAL rules. The use of the Asian Development Bank's name for any purpose other than for attribution, and the use of the Asian Development Bank's logo, shall be subject to a separate written license agreement between the Asian Development Bank and the user and is not authorized as part of this CC-IGO license. Note that the link provided above includes additional terms and conditions of the license.

The images or other third party material in this chapter are included in the chapter's Creative Commons license, unless indicated otherwise in a credit line to the material. If material is not included in the chapter's Creative Commons license and your intended use is not permitted by statutory regulation or exceeds the permitted use, you will need to obtain permission directly from the copyright holder.

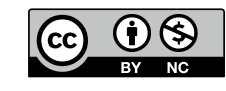

